\title{
REDES DE EDIÇÃO E REDES SOCIAIS: CRUZAMENTOS E QUESTÕES
}

\author{
Ana Elisa Ribeiro*
}

RESUMO: Com base na noção de "redes de edição" (Martins 2005), este trabalho discute as relações entre editores de literatura contemporânea, especialmente os de pequenas casas editoriais, a tecnologia e as redes sociais. Foram feitas entrevistas com alguns ativos editores atuais para se aborda temas como o uso das redes para a publicação e divulgação dos livros literários. Considera-se que editores e autores têm consciência dos fluxos em que estão inseridos e de que são também, protagonistas; sabem que podem empregar novos espaços digitais para potenciar suas produções, do ponto de vista da criação e da difusão; atribuem-se papéis mesclados, o que está bastante distante da visão segundo a qual haveria uma divisão do trabalho que separaria autores e editores além disso, têm, em sua maioria, uma relação positiva com tecnologias digitais e as empregam a seu favor.

PALAVRAS-CHAVE: Produção editorial; Livro; Redes sociais.
* anadigital@gmail.com

Professora do Centro Federal de Educação Tecnológica de Minas Gerais - CEFET/MG, doutora em Linguística Aplicada (Linguagem eTecnologia) pela UFMG.

ABSTRACT: Based on the concept of "publishing networks" (Martins, 2005), this paper discusses the relationship between contemporary literature publishers, especially in small business, technology and social networks. Interviews were made with some active current editors to address issues such as the use of networks for publication and dissemination of literary books. It is considered that publishers and authors are aware of the streams where they live and who are also actors in this field; they know that they can hire new digital spaces to boost their production, from the point of view of creation and dissemination; they attribute is merged roles, which is far removed from the view that there would be a division of labor that would separate authors and publishers: moreover, they have mostly a positive relationship with digital technologies and employ it in their own favor.

KEYWORDS: Editorial production; Book; Social networks. 
1. MARTINS. Profissões do lirvo.

2. ARAÚJO. Uma tecnologia na mão e uma ideia na cabeça: pequenas editoras, autores independentes e as novas possibilidades de publicação de livro.

3. Modelo de financiamento em que o editor-autor propõe a publicação por meio de uma plataforma digital e o público investe quantias variáveis, acreditando no projeto. É uma espécie de "vaquinha" ou venda por assinatura.

4. Grosso modo, não existem mais obras analógicas, se pensarmos que mesmo os livros impressos são produzidos a partir de um arquivo digital. 0 mesmo arquivo pode gerar produtos com modalizaçoes diversas, assim como ensejar práticas de leitura diferenciadas.

\section{CONSIDERAÇÕES INICIAIS}

Um fluxograma tradicional de edição de livros impressos - apenas para tomar um exemplo de produto editorial - teria início no "original" de uma obra e desaguaria nas estratégias estudadas e trabalhadas para que esse livro chegasse até seu público. Em condições analógicas, esse texto original existiria na forma de cópias físicas manuscritas ou datilografadas, o que é sensivelmente diferente dos originais digitais que hoje existem.

Jorge Martins ${ }^{1}$ afirma, no entanto, que a edição de um livro começa muito antes de sua existência como texto, sendo possível criar a necessidade dele antes mesmo de encomendá-lo a um autor. Em muitos casos, os livros - analógicos ou digitais - se vendem antes de existirem propriamente, como mostra Pablo Araújo ${ }^{2}$, se pensarmos especificamente em modelos de financiamento como o crowdfunding ${ }^{3}$.

Tanto para editores quanto para escritores, as formas de produzir livros passam por mudanças importantes, isso pelo menos desde os anos 1970, quando obras "marginais" começaram a circular depois de feitas por meio de tecnologias menos restritas, como o mimeógrafo, por exemplo No entanto, a chegada de tecnologias digitais cria redes de conversação em torno das obras e modos de distribuí-las que transformam toda a rede editorial, incluindo-se seu processo produtivo mais original ${ }^{4}$.
Ao contrário do que apregoa um discurso segundo o qual o livro é um objeto para ser lido de forma solitária ou para "viajar", tanto em Bahloul (2002) quanto em Bayard (2007) é possível divisar como a leitura e o livro participam, fortemente, das redes sociais e ajudam a estreitar laços. Segundo Bahloul ${ }^{5}$

a leitura não é uma prática social apenas porque classifica ou está classificada na hierarquia dos níveis sociais, mas também porque dá origem a interações e intercâmbios sociais. Tampouco é, como afirma a representação tradicional, um ato de intimidade pura ou de retraimento individualista ilhado do mundo e da sociedade. A leitura está totalmente imbricada na organização e nas condições sociais. A iniciativa da leitura, a recepção e a circulação dos conhecimentos adquiridos, as representações do livro e da leitura atuam no marco das "redes" de socialização.

Araújo ${ }^{6}$ formula a seguinte pergunta, a partir do estudo que empreende sobre a formação de uma biblioteca privada, no início do século XX, em Belo Horizonte, MG: "Que processos e redes sociais interferem na formação de uma coleção?”, o que demonstra que há indícios da rede registrados nos objetos e nas coleções particulares.

Este trabalho trata das formas atuais de se pensar uma obra, especialmente a impressa, e se fundamenta na experiência de um grupo contemporâneo de editores, escritores e
5. BAHLOU. Lecturas precárias. stúdio sociológico sobre los "poço lectores", p. 31. (tradução minha).

6. ARAÚJO. Colección: reflexione sobre una biblioteca particular, p.20-21. (tradução minha).
EM TESE
BELO HORIZONTE
v. 20
N. 3
SET.-DEZ. 2014
RIBEIRO. Redes de edição e redes sociais: cruzamentos e questões
P. $163-179$

\section{Tradução e Ediç̧ão}


7. RECUERO. $A$ conversação em rede. Comunicação mediada pelo computador e redes sociais $n$ internet, p.127. escritores-editores brasileiros muito atuante nas "redes sociais". Estas, que sempre estiveram em ação para a movimentação dos textos, são, agora, somadas às tecnologias digitais, o que parece transformar um tanto a atividade destes profissionais.

\section{REDES SOCIAIS}

As redes sociais sempre existiram, não sendo de outra forma que interagimos no mundo, desde tempos remotos. A expressão ganha nova roupagem na atualidade por conta das tecnologias digitais que as transformam em conexões explí citas em ambientes eletrônicos. As redes sociais de Clarice Lispector, por exemplo, brevemente descritas em Ribeiro (2013, 2013a), são as responsáveis pela dinâmica de publicacão e divulgação de uma das escritoras mais consagradas do Brasil, inclusive nas atuais "redes sociais".

Redes sociais sempre interessaram mormente à Sociologia campo do saber frequentemente invocado para tratarmos do assunto. Recuero (2009) acusa a existência desses estudos ao longo do século XX e passa, então, ao estudo das "redes sociais na internet”, considerando as mudanças importantes que a informática trouxe para as conexões entre pessoas e seus capitais sociais (numa alusão ao sociólogo Pierre Bourdieu, conhecido pela ideia das "trocas simbólicas")

Segundo Raquel Recuero7, as "redes sociais" são "uma metáfora estrutural. Ou seja, as redes são metáforas para os grupos humanos, onde se procura compreender suas inter-relações”. Na obra de $2009^{8}$, a autora afirma que as redes sociais na internet têm características próprias. São formadas pelos "atores" e pelas "conexões" entre eles, no entanto, de maneiras diferenciadas daquelas já descritas para as interações no mundo analógico.

O sociólogo Manuel Castells (2007) atribui o início das "redes sociais" na internet à criação do Minitel francês, um dispositivo de 1978, que permitiu aos indivíduos se conectarem e tratarem de suas vidas pessoais. Na obra de Castells (2007a), ele mostra uma série de estudos que oscilam entre considerar a internet um ambiente mágico de sociabilidades ampliadas e, ao contrário, tratá-lo como perigoso e alienante. O fato, no entanto, é que, segundo Castells ${ }^{9}$, o computador a internet criam "novos suportes tecnológicos para a sociabilidade, que eram diferentes, mas não por isso inferiores, às formas anteriores de interacção social”. Segundo o autor, a emergência do que ele chama de "individualismo em rede" é um modelo social amplamente propiciado pela Internet $\mathrm{e}$ que vem ganhando espaço entre todos nós.

O individualismo em rede constitui um modelo social, não uma colecção de indivíduos isolados. Os indivíduos constroem as suas redes, on-line e off-line, sobre a base dos seus interesses, valores, afinidades e projectos. Devido à flexibilidade e ao
8. RECUERO. Redes sociais na Internet, p.25.

9. CASTELLS. A galáxia Internet Reflexões sobre Internet, negócios e sociedade, p.155.
EM TESE
BELO HORIZONTE
v. 20
N. 3
SET.-DEZ. 2014
RIBEIRO. Redes de edição e redes sociais: cruzamentos e questões
P. $163-179$

Tradução e Ediç̧ão 
10. CASTELLS. A galáxia Internet. Reflexões sobre Internet, negócios e sociedade, p.161.

11. MARTINS. Profissões do livro, $\mathrm{p}$. 267

12. MARTINS. Profissões do livro, $\mathrm{p}$ 53.

13. MARTINS. Profissões do livro, p. 53. poder de comunicação da Internet, a interacção social on-line desempenha um papel cada vez mais importante na organização social no seu conjunto. Quando se estabilizam na prática, as redes on-line podem construir comunidades, ou seja, comunidades virtuais, diferentes das comunidades físicas, mas não necessariamente menos intensas ou menos eficazes em unir e mobilizar..$^{10}$

É nesse "unir e mobilizar" que parecem se concentrar editores e escritores, na busca de autores novos, novos livros e pela difusão, ao fim e ao cabo, da (sua) literatura. É num outro sociólogo, no entanto, que encontramos a redefinição da "cadeia do livro" como, na verdade, uma rede de interações para a mediação do livro (Martins, 2005). Jorge Martins trata dos "atores sociais do livro"11 além de nos oferecer duas definições importantes para este trabalho, quais sejam a de edição como "actividade que consiste em orquestrar os diferentes processos que transformam em um objecto impresso (pronto a ser distribuído aos leitores) aquilo que não passava de projecto no espírito do autor"12 e a de editor:

alguém capaz de coordenar múltiplas operações, como as de seleccionar (escolher, separar, recusar, preferir, decidir...) e preparar originais, planificar e gerir as diferentes etapas da transformação dos originais em obras e fazer com que estas cheguem ao mercado a que se destinam. ${ }^{13}$
Para Martins ${ }^{14}$, "o bastião central da resistência às forças do mercado é hoje constituído por pequenos editores inovadores e virtuosos por obrigação", o que nos aproxima dos sujeitos que serviram como fontes deste trabalho.

Num venerável movimento de independer das grandes editoras - cujos processos estão ligados à estabilidade e às certezas possíveis -, desde sempre os próprios autores tentam se empoderar, inclusive em termos de meios, recursos e competências, para atuar por conta própria, e tornam-se editores (de si e dos outros). Computadores e editores de texto/imagem inserem-se nesse processo, permitindo que pessoas antes alijadas da rede editorial ou dependentes de um processo "profissional" possam, elas mesmas, geralmente os próprios autores, tornar-se editores e atuar, até um tanto guerrilheiramente, nesse campo. $\mathrm{Na}$ atualidade, tornam-se, então, escritores-editores-marketeiros-distribuidores-vendedores, entre outras atribuições - das quais não se furtam. Nesse movimento, novos autores se lançam, tornam-se conhecidos e disputam lugares na memória da cultura e no cânone. A despeito de todo este trabalho numa esfera ainda não canônica, é comum que estes pequenos autores, ao tornarem-se conhecidos e respeitados, tratem logo de aceitar convites das grandes editoras, o que, ao cabo, parece que é o que sempre almejaram.
14. MARTINS. Profissões do livro, $\mathrm{p}$. 264.
EM TESE
BELO HORIZONTE
v. 20
N. 3
SET.-DEz. 2014 RIBEIRO. Redes de edição e redes sociais: cruzamentos e questỗes
P. $163-179$

Tradução e Ediç̧ão 
15. Em ordem alfabética: Carlos Fialho (editor e autor, editora do Norte) Carlos Henrique Schroeder (editor e autor e-Galáxia, Formas breves, Santa Catarina), Eduardo Lacerda (escritor e editor, editora Patuá, Araxá, Minas Gerais) Mário Alex Araxá, Minas Gerais), Mário Alex plástico, Belo Horizonte Micheliny Verunsschk (escritora, Olinda PE), Rafael F. Carvalho (linda, PE), Rafael F. Carvalho Aleixo (escritor, performer, editor, Aleixo (escritor, performer, editor, (escritor, Belo Horizonte).

\section{DINÂMICA DO TRABALHO}

Grande parte dos editores de pequenas editoras, no Brasil, é, antes de tudo, autor. Com a ampliação do "poder semiótico" (KRESS, 2003) de todos nós por conta dos equipamentos disponíveis e da relativa facilidade de aprendermos novos modos de expressão, muitos autores tornam-se editores de seus próprios projetos, que resultam em materialidades que nada deixam a desejar em relação aos livros de editoras de grande porte. Os livros da Editora Patuá, de São Paulo, ou da Jovens Escribas, de Natal, por exemplo, são tratados, em termos gráficos e projetuais, com o mesmo profissionalismo que qualquer outra editora dispensaria.

Em razão disso e de muitos desses editores/autores estarem nas "redes sociais", especialmente no Facebook e no Twitter, solicitamos a nove ${ }^{15}$ deles que respondessem a um breve questionário padronizado. As perguntas dirigidas a todos foram:

[1] Como e quando você entrou nas redes sociais e em quais delas? (Twitter, Orkut, Facebook, outras)

[2] Em que proporção os usos que você faz de redes sociais digitais está ligado à sua atividade como editor ou autor?

[3] Que usos autorais/editoriais você faz das redes?

[4] Que resultados e efeitos você percebe nesses usos?
[5] Os efeitos e resultados se comparam aos tempos de edição antes das redes?

[6] Conte algun(s) caso(s) bem evidente pra você que jamais teria acontecido sem redes sociais digitais (caso de edição, autoria, vendas, etc.)

[7] Como é seu fluxo editorial hoje? (autor: escrita, envio, contatos, divulgação, etc.) (editor: recebimento de originais, contatos, vendas, etc.)

Todos os editores e autores contatados responderam às questões, a maioria preferindo que as respostas fossem entregues por e-mail. De posse desses textos, passamos à organização do material, no sentido de mostrar como esses "atores sociais do livro" têm entendido e empregado as "redes sociais" na Internet para a consecução de seu trabalho, geralmente ligado à publicação de obras literárias. Certamente, é a movimemtação deles que vem movendo, também, o mecanismo de renovação da literatura nacional.

\section{DISCUSSÃO}

Dos nove "atores sociais do livro" entrevistados, ao menos quatro são reconhecidos como editores, tanto de seus próprios trabalhos quanto de outros. Carlos Henrique Schroeder, de Santa Catarina, Carlos Fialho, do Rio Grande do Norte, Mário Alex Rosa e Ricardo Aleixo, de Minas 
Gerais e Eduardo Larcerda, de São Paulo, são empreendedores conhecidos por sua atuação na edição de obras e eventos recentes. Todos são, também, escritores atuantes, de prosa ou verso.

Os demais entrevistados são as poetisas Micheliny Verunschk, de Pernambuco, e Líria Porto, de Minas Gerais, além do contista Rafael F. Carvalho, de São Paulo e do romancista, contista e poeta Sérgio Fantini.

\section{REDES SOCIAIS: QUANDO E QUAIS?}

Todos os entrevistados têm uma história de atuação com tecnologias e redes sociais. A primeira questão apenas perguntava sobre quais "redes" eles usavam e desde quando, o que só podia obter respostas muito recentes. Para o caso o Orkut foi muito citado entre os autores e editores (4) sendo que também seu abandono ou substituição é comum, como afirmam, por exemplo, Carlos Schroeder e Carlos Fialho:

"Eu entrei no Orkut logo no princípio, mas quando fui para o Facebook deletei minha conta”. (Schroeder)

"Orkut, 2005. Encontra-se abandonado desde 2010, acho." (Fialho)

Ou Rafael Carvalho:
"Entrei em 2004, no Orkut, mas tive um pequeno hiato, de um ano e meio, dois. Aí voltei em 2007. Em 2010, acho, que comecei a usar o Facebook. Encerrei o Orkut e só uso o Facebook, nada mais".

Os usos do Facebook e do Twitter são prolíficos entre os editores e autores. Carlos Schroeder, por exemplo, afirma, em relação a usos e preferências:

"Uso o twitter há pelo menos cinco anos, é meu xodó, pela rapidez e objetividade, mas ando usando mais o Facebook ultimamente, por causa da caixa de mensagens, que se tornou minha caixa oficial de mensagens."

Sérgio Fantini assim define sua entrada nas redes:

"Entrei no FB em 2011, em princípio apenas para acompanhar as postagens de Braúlio Tavares, que enviava e ainda envia pacotes de seus textos por e-mail. Entrei sem saber nada. Sempre tive, cronologicamente, resistência a computador, internet, e-mail, Orkut, baixar coisas... Por ora, cheguei ao FB, mas não devo ir muito além disso.

Embora não se atribua um perfil de usuário convicto dessas tecnologias, o escritor parece reconhecer nelas um potencial importante de troca e interação, motivo pelo qual ele adere à mediação pelo computador. Já os casos de Micheliny 
Verunschk, Mário Alex Rosa e Carlos Fialho são de adesão recente, embora a menção aos blogs nos remeta a outras formas de contato e interação via rede:

"Nunca usei Orkut. Entrei no Twitter e no Facebook em 2011 Já os blogs, uso desde 2004." (Micheliny V.)

"Comecei em 2012 e, de todas, a que mais me interessou foi o Facebook." (Mário Alex Rosa)

"Twitter, em maio de 2009. Facebook, em 2011. Instagram, em 2013." (Fialho)

Os blogs, estes sim, considerados como plataformas de exposição dos textos e diálogo com o leitor, parecem ser o espaço de fundação das relações entre estes "atores sociais do livro" e as "redes sociais", inclusive propiciando uma relação sustentada há mais de uma década, em alguns casos. Tanto a migração de umas redes para outras quanto a manutenção dos blogs ocorre nestes casos. Líria Porto e Ricardo Aleixo dão seus depoimentos:

"No começo, eu escrevia no Word, perdi uma série de arquivos, então minha amiga, a escritora Roberta Silva, fez meu blogue, tanto mar, onde até hoje guardo tudo que escrevo (no momento, o blogue é fechado para o público, só eu entro lá para postar ou reescrever algum poema). A seguir, a Rober- ta criou para mim o Orkut, usado raramente, e, um tempo depois, insistiu para que eu participasse do Twitter (este eu não quis mesmo). Demorei a me interessar pelas redes sociais. Surgiu o Facebook e a Roberta me apresentou à novidade... Estou convencida de que é neste ambiente que a minha escrita mais se expande e é no Facebook que publico grande parte da minha produção literária." (Líria Porto)

"Entrei em 2004, quando abri um blog (www.jaguadarte.zip net) e, por muito pouco tempo, sem nem mesmo dizer que aprendi a fazer as coisas direito por lá, o Orkut." (Ricardo Aleixo)

Já a resposta de Eduardo Lacerda traça um histórico da web como espaço de interação e trocas, de diversas espécies, sendo interessante apontar que o editor da Patuá começa pelos chats, ferramenta de sucesso nos anos 1990:

"Acredito que uma parte dessa geração com idade entre 30 e 40 anos foi a primeira a ter contato com a internet ou pelo menos com uma internet rudimentar, mas que se tornaria o que é hoje. E uma das primeiras redes sociais com que tive contato foram os chats. Não são exatamente redes sociais, mas através de chats tive as primeiras experiências de relações virtuais (amizades e também relacionamentos) e, ainda hoje, acredito que são ferramentas importantes também para o meu trabalho. Já 
conheci escritores e colaboradores através desse recurso. Após isso, antes mesmo do Orkut, o ICQ (I seek you - eu sigo você) permitia criar perfis públicos rudimentares, mas que expandiram a interação de grupos. Depois acabei, como quase todas as pessoas, utilizando o Orkut e, hoje em dia, principalmente o Facebook. Nunca achei o Twitter uma ferramenta tão interessante, não consigo estabelecer relações com tão poucas palavras. Como escritor, a primeira rede social que utilizei foi um site chamado Ponto de Vista, que permitia criar um pequeno perfil público, postar contos e poemas e comentar os textos de outros colaboradores."

Essas pecepções dos usos das redes sociais mediadas por computador podem ser melhor explicitadas nas respostas subsequentes.

\section{USOS DAS REDES PARA AUTOR E EDITOR}

Os usos das redes pelos atores sociais, neste caso, dos livros, é que definem novos modos de atuação e difusão de suas escritas e materiais publicados. Usos para a divulgação e a escrita parecem estabelecidos nesses ambientes, que terminam por criar uma rede de autores, editores e leitores, desde que nos lembremos que essas atuações são cada vez menos distintas, dado que as tecnologias de edição (softwares, especialmente) podem chegar às mãos de todos.
O depoimento do editor Carlos Henrique Schroeder é emblemático, neste sentido. Ele afirma:

"Como editor e produtor de eventos literários, as redes sociais são meu segundo escritório, é onde eu consigo acompanhar o que está acontecendo no mercado, contatar agentes, escritores, outros editores, onde consigo ver o que está acontecendo no mercado internacional. Eu moro numa pequena cidade em SC, e daqui eu acompanho o que editoras inglesas, chilenas e alemãs andam aprontando, e tudo pelas redes sociais. As redes sociais são minha conexão com o mundo. Hoje mesmo, fechei uma parceria com uma editora islandesa, através de mensagens no Facebook, e finalizamos o papo pelo Skype.”

Algo semelhante ocorre a Sérgio Fantini, Carlos Fialho, Mário Alex Rosa, Rafael Carvalho e Ricardo Aleixo:

"Numa proporção bem grande: consumo arte no FB, me informo do 'cenário', dialogo com todas as instâncias, divulgo minhas atividades (raramente textos literários) e meu blog..." (Fantini)

"A Internet é a melhor amiga do pequeno editor e a principal mídia (porque permite custos mais em conta) para as editoras com baixo poder de investimento." (Fialho) 
"Divulgo atualizações do meu blogue pessoal (que acaba sendo promoções dos meus textos autorais), lançamentos, disponibilidade de livros na nossa loja virtual, ações da nossa editora. Enfim, o que for preciso." (Fialho)

"Sem dúvida, as redes sociais mudaram e mudarão mais aind as relações entre as pessoas, digamos 'comuns' e as pessoas do meio literário. Tanto como editor e autor vêm sofrendo mudanças para o bem e para o mal, pois recebemos mais originais via on-line, afinal nossos endereços estão disponíveis nesse mundo virtual. Sou da época de cartas, ansiedade para receber um comentário de um poema enviado numa carta ou mesmo um livro. Hoje você manda um poema ou mesmo mand o livro em pdf e aí um amigo já responde rapidamente que recebeu e que vai ler. Depois disso, muitos hiatos. Por outro lado, um poema pode circular mais rápido, mais pessoas lendo. Vejo com bons olhos essas mudanças, ainda que sobre menos tempo. Mas o que é o tempo? 24 horas." (Mário Alex Rosa)

"É o meio de divulgação disponível para pequenos autores. $\mathrm{Eu}$, por exemplo, não tenho recursos para colocar em outro lugares - livrarias, etc. - mas nem me incomodo, as livrarias não se interessam por autores iniciantes." (Rafael Carvalho)
" $80 \%$ da minha atuação nas redes sociais tem como objetivo a divulgação, a comercialização e o debate sobre o que faço." (Ricardo Aleixo)

As redes sociais são empregadas para potenciar ações de autoria e divulgação que seriam impossíveis ou mais difíceis sem essas tecnologias. Isso faz com que os próprios autores se coloquem como agentes de seus textos e livros, muito embora alguns demonstrem resistência em publicar inéditos no Facebook, por exemplo.

A informação chega mais rápido, assim como os retornos sobre textos publicados. Uma grande conversação ocorre e os contatos podem ser feitos, independentemente de onde as pessoas residem, como afirmou Schroeder, na confirmação de um apontamento importante de Castells ${ }^{16}$. As redes sociais são, ainda, residenciais e geográficas, mas são tanto mais ainda virtuais, descolando, em alguma medida, as pessoas de seus locais de morada. A circulação dos textos e a conversação terminam por resolver uma parte do que, antes, teria de ser feito presencialmente. É o que aponta, também, a poetisa pernambucana Micheliny Verunschk:

"Uso da forma mais prática possível, mesmo porque alguns contatos estão muito distantes. Nesse sentido, melhorou muito, pois podemos resolver em minutos certos problemas editoriais. Mas sinto falta do encontro. Veja bem, não quero ser

\begin{tabular}{|c|c|c|c|c|c|c|}
\hline EM TESE & BELO HORIZONTE & v. 20 & N. 3 & SET.-DEZ. 2014 & RIBEIRO. Redes de edição e redes sociais: cruzamentos e questões & P. $163-179$ \\
\hline
\end{tabular}

\section{Tradução e Ediçãa}


saudosista e não sou, apenas gostaria de ver e ouvir mais as pessoas."

"Escrevo quase que diariamente no Facebook. Quando digo escrevo trata-se de poemas em séries, pequenas narrativas etc. Mantenho contato com outros autores, muitos deles jovens e inéditos em livro. Divulgo meu trabalho e o trabalho de amigos."

Em relação à publicação direta de textos inéditos em plataformas de redes sociais, os autores divergem um pouco Fantini já havia declarado evitar a postagem de seus textos. O mesmo pensa Carlos Henrique Schroeder, em relação aos próprios textos, mas explica, em relação à sua atuação como editor:

"Para escrever, fico longe das redes sociais, pois concentração é imprescindível. Mas para editar, uso muito a rede, troco informações com os autores, aprovo material, e já mando mais mensagens pelo Facebook do que e-mails. Sei que logo o Twitter e o Facebook devem acabar, é só uma onda, mas surgirão outras redes sociais, mais completas ainda. Eu e o Tiago Ferro tocamos uma coleção de literatura inteiramente pelo Facebook, conversamos diversas vezes por dia pela caixa de mensagem, só por mensagem. Recebo originais também pelo Facebook."
A poetisa mineira Líria Porto emprega os espaços virtuais como cadernos, só que procurando um diálogo muito mais intenso. Segundo ela:

"escrevo todos os dias, posto todos os dias no blogue e no $\mathrm{Fa}$ cebook - leio muita gente também."

Mas, a faceta da divulgação nunca está esquecida, segundo continua Líria:

"A possibilidade de interação, de troca, de visibilidade. Mas é tudo muito rápido, precisa ter um ritmo constante."

Dão reforço a essas ideias os seguintes depoimentos:

"Uso Facebook ora como rascunho da minha produção e, desse modo, também como ferramenta de difusão." (Mário Alex Rosa)

"Divulgo meus contos nas redes, mas nem sempre. Acho que cansa para as pessoas, tem autor que coloca textos diariamente. Parece que somos obrigados a ler, satura muito rápido." (Rafael Carvalho)

"Uma larga faixa do que posto, em termos de material inédito, é pensada e produzida diretamente na caixa de texto do 
Facebook. São textos que não existiriam de outra forma, mas que acabam sendo reaproveitados em outros suportes: transformam-se em canções, videopoemas ou são posteriormente publicados em mídia impressa. Também republico com frequência coisas que já soltei em livro, em publicações diversas ou nos meus blogs." (Ricardo Aleixo)

Parece importante mencionar, conforme mostram esses depoimentos, que os papéis de autor, editor e divulgador são exercidos por todos os entrevistados (e por muitos outros no planeta), em momentos e condições diversos, distintos por eles mesmos, que terminam por compreender e perceber uma espécie de melhor gestão do uso das redes sociais para a edição.

Para Eduardo Lacerda, no entanto, a rede foi porto de partida para uma intensa produção "real", de livros impressos, e alimenta fortemente as atividades da editora Patuá:

"A própria existência e relativo sucesso da proposta da Patuá dependem do bom uso dessas ferramentas. Acredito que seria impossível a nossa atividade se não fosse a existência do Facebook. Seriam impossíveis a recepção, a avaliação, a divulgação e as vendas de tantos livros, como temos feito."

Um emaranhado de relações e redes parece ter sido formado, sendo o editor um elo forte entre pessoas e seus trabalhos. Sem as redes, reais e virtuais, grande parte da energia vital da Patuá (e de muitos outros projetos, acredito) estaria comprometida.

\section{COMPARAÇÃO ANTES DAS REDES}

É certo que todos os autores e editores aqui mencionados têm prolíficas redes sociais, dentro e fora da Internet. É dessa forma que a literatura se faz e se mantém, no mínimo porque um autor e um editor precisam interagir com leitores.

$\mathrm{Na}$ comparação entre tempos atuais, de redes virtuais, e tempos idos, os depoimentos apontam a rapidez e a capilaridade como elementos interessantes dos meios atuais. Os depoimentos de Mário Alex Rosa, Micheliny Verunschk e Rafael Carvalho tocam nesses aspectos:

"Antes você recebia via correio, ainda acontece com os melhores editores. Mas o mundo virtual certamente diminuiu o tempo de espera. Com o tempo poderemos avaliar melhor essas mudanças, mas é bem provável que o futuro do livro será outro que não esse que conhecemos." (Mário Alex Rosa)

"Não saberia avaliar ao certo, mas creio que os efeitos em rede são ampliados pela própria velocidade do sistema. Mas acredito também que tudo se esvai muito rápido para o leitor. Não é uma afirmação categórica. É uma impressão." (Micheliny V.) 
"Hoje, a difusão, o alcance das redes, é muito grande, você atinge bastante gente." (Rafael Carvalho)

Eduardo Lacerda menciona questões tecnológicas que, para ele, são determinantes para editoras pequenas, nos dias de hoje:

"Iniciei o trabalho de edição com livros após a popularização das modernas redes sociais (tive experiências anteriores com a edição de uma revista literária, mas com circulação quase que exclusivamente dentro da Universidade de São Paulo). Acho que dois movimentos permitiram esses resultados: o primeiro é a possibilidade da impressão sob demanda, que não existia há menos de 10 anos; o segundo, a criação das modernas redes (especialmente Orkut, Facebook e Twitter). São fatos confluentes na área editorial, para as editoras pequenas e independentes, e que permitiram a criação de centenas de novas editoras em todo o país. Não haveria nenhum resultado para a Patuá, que não existiria, se não fossem esses dois fatores tecnológicos."

"Como a maior parte dos autores chegaram através de divulgação em redes sociais, nossa divulgação é realizada através delas, assim como as vendas, que utilizam apenas nosso site (que as pessoas acabam conhecendo através das redes). Acredito, como disse, que devemos muito à existência delas.”
Enquanto outros atores demonstram ainda mais dúvida quanto aos efeitos das redes sociais na Internet:

"O FB é incomparavelmente mais interessante nessa área como também na social e 'de lazer'. É quase uma revolução para mim - ainda em andamento, sub judice, sujeita a reavaliações futuras." (Fantini)

“Já entrei no mercado quando existia Internet. Mas acredito que os resultados são muito melhores porque dispomos de mais canais de comunicação para atrair leitores." (Fialho)

"Para o autor desconhecido, a rede social tem peso. Há muitas revistas digitais, muitos sites de boa qualidade literária - acaba sendo reconhecido por editores desses espaços virtuais e sua obra é divulgada." (Líria Porto)

\section{FLUXO EDITORIAL ATUAL}

No início deste trabalho, mencionamos os fluxos editoriais analógicos, em que um original passava por uma série de tratamentos até alcançar a divulgação. $\mathrm{Na}$ atualidade e com o uso das redes sociais na Internet, a percepção desses fluxos parece ter se alterado um pouco, como narram os entrevistados. 
No caso dos editores, e mesmo de autores, alguns depoimentos apontam questões de recepção de originais, divulgação necessariamente pelas redes sociais e mesmo um trâmite completamente ligado a tecnologias como e-mails e caixas de mensagens.

"Recebo os originais, faço um orçamento envolvendo todos os profissionais, digramamos o livro e fazemos a arte de capa, revisamos gramaticalmente, aprovamos o resultado com o autor, mandamos pra gráfica, marcamos o lançamento e começamos a divulgar através de e-mail marketing, assessoria de imprensa e campanhas em redes sociais." (Fialho)

"Assinei contrato com a editora Lê e os livros estão prestes a sair (é uma editora de alcance nacional, creio que muita coisa pode acontecer) e estou em adiantadas conversações com a Patuá." (Líria Porto)

"Meu trabalho editorial envolve muito mais do que a edição do texto. Sou responsável por tudo dentro da editora e gosto disso. Recebo os originais, uma média de 100 a 150 por mês, respondo todos os e-mails, realizo as leituras (de quase todos os livros que chegam, pelo menos das primeiras páginas), atualizo o site, realizo a divulgação, embalo os livros vendidos, organizo os lançamentos, edito, reviso, tiro ISBN, pago as contas (vou a quatro bancos por dia), vou aos Correios, con- firo se os livros foram entregues, formato contratos com os autores, envio livros para jornalistas, emito notas fiscais, faço tudo o que for necessário para a editora. Muitas dessas funções realizo pelo Facebook, como a divulgação (realizada quase que exclusivamente por esse canal)." (Eduardo Lacerda)

No caso dos escritores e de escritores que tomam para si a tarefa de editores, para autopublicação, alguns depoimentos dão a ideia de que nem tudo esteja resolvido pela existência da Internet. A despeito de um discurso que julga as redes sociais muito ágeis e de vasto escopo, não é isso que pensa, por exemplo, o escritor Sérgio Fantini, que questiona a efetividade da rede como formadora de leitores e de público para os eventos nela divulgados, todo o tempo:

"Em relação ao FB, o que pode ter mudado é a frustração de acreditar que a rede seria muito mais eficiente para divulgar atividades. Esse resultado pífio talvez se deva ao fato de que centenas de outras pessoas também estejam fazendo o mesmo e com isso há uma oferta excessiva e até mesmo uma rejeição do receptor por ter tanta oferta."

Ricardo Aleixo, por sua vez, trata cada livro como um objeto distinto, inclusive do ponto de vista dos fluxos editoriais, especialmente quando é seu próprio editor. Enquanto Mário Alex Rosa apresenta uma visão quase desvinculada dos processos digitais, mencionando apenas a importância 
das vendas pelo site ou do comércio eletrônico para uma livraria física (o que não é pouco, diga-se).

"Na verdade, publico menos do que gostaria. Não tenho um fluxo editorial definido - quando sou meu próprio editor, faço as coisas de modo muito diferente do que quando publico por uma editora. Arrisco-me a dizer que cada livro instaura um processo diferente." (Ricardo Aleixo)

"Uma das coisas que prefiro evitar é o contato com o autor $\mathrm{Na}$ Scriptum, os autores deixam lá as cópias e os responsáveis repassam para os editores. Pedimos um prazo de 3 meses, mas pode variar para mais ou menos, pois todos os editores têm outros trabalhos. As vendas melhoraram muito com o site, ainda que recente. Procuramos cuidar o máximo dos nossos autores, ainda que sejamos uma editora pequenininha e com poucos recursos financeiros. Uma das alegrias é ver alguns escritores que começaram na Scriptum e que estão voando alto. A leitura continua sendo o maior prazer, melhor ainda quando nos tornamos amigos. Felizmente isso tem acontecido. É o bem da vida." (Mário Alex Rosa)

\section{ALGUNS CASOS}

Os casos de processos de edição sobre os quais a intervenção das tecnologias digitais é evidente são lembrados por esses editores e autores, especialmente como potenciação do alcance e dos contatos sociais. Para alguns, especialmente escritores sem atuação como editores, a venda pela Internet é aspecto suficientemente relevante, como mencionou Rafael Carvalho. Para outros, como Ricardo Aleixo, no depoimento a seguir, o contato com o leitor é uma expansão que marca a carreira do artista:

"Não tenho propriamente um caso para contar. Em 2004, com a inclusão do livro A roda do mundo (meu e de Edimilson de Almeida Pereira) no vestibular da UFMG, era bastante intenso o contato dos estudantes comigo. Muitos queriam que eu explicasse os poemas, outros só queriam falar do que gostaram, havendo também os que maldiziam o livro, por não conseguirem entendê-lo. Foi muito bom viver aquele momento único - novo tanto para mim quanto para os leitores."

Eduardo Lacerda, editor da Patuá, cuja trajetória é fortemente marcada por questões ligadas à web, reforça a menção à caça e à descoberta de autores, o que potenciou, certamente, seu status de editor disputado, nos dias de hoje:

"Quase todos os escritores que já publiquei (e já são mais de 200) conheci - direta ou indiretamente - através da internet / redes sociais. No início da Patuá, apesar de ter dezenas de amigos escritores e ter editado um jornal chamado O Casulo 
(premiado pela Prefeitura de São Paulo e que chegou a ter tiragem de 30 mil exemplares), poucos confiavam que o projeto da editora fosse consistente. Tivemos de ir atrás de escritores desconhecidos na internet. Em 2010, ano de criação da editora (efetiva e afetivamente, consideramos fevereiro de 2011 como o ano de criação da editora, pois foi quando publicamos nosso primeiro título, mas o trabalho de criação da editora começou mais de dois anos antes), fui contratado para trabalhar no stand da Volkswagen, na Bienal do Livro de São Paulo. Meu trabalho consistia em tuitar tudo o que estivesse ocorrendo na feira, no stand da Volks e no da Secretaria de Estado da Cultura (trabalhava no Programa São Paulo: um Estado de leitores e, entre minhas funções, desenvolvia projetos de estímulo à literatura além da produção de eventos culturais). Aproveitei os dias que passaria na internet para tuitar sobre a criação, a proposta e os objetivos da editora e para procurar escritores em outras redes sociais (ainda utilizava apenas o Orkut e não tinha perfil no Facebook). Recorri também a um site chamado Recanto das Letras. Lá eu conheci a Juliana Bernardo, primeira autora publicada pela Patuá e também o escritor Willian Delarte, que seria o quinto ou sexto autor publicado. Hoje recebo em torno de 100 a 150 originais por mês, não é mais necessário que eu procure autores para publicação, já que eles têm nos procurado. $\mathrm{O}$ que acontece, atualmente, é que acompanho pelo Facebook as postagens de textos de alguns escritores e, se acho consistente, acabo convidando para publicação. Penso que, de alguma forma, todos os processos editoriais dependem um pouco das redes sociais, desde a seleção de autores, já que, muitas vezes, acompanho a produção imediata ou a recepção imediata por parte dos leitores, e isso influencia nessa seleção dos autores e originais para publicação, até a percepção de quais projetos são aceitos com mais facilidade ou maior intensidade, assim como a divulgação depende quase que exclusivamente da existência delas, as redes sociais (especialmente o Facebook).”

Líria Porto e Micheliny Verunschk, também autoras sem atuação de editoras, apontam a "escrita aberta", isto é, a prática da escrita on-line, diante dos olhos do leitor, inclusive contando com sua intervenção, caso da poetisa pernambucana; e os contatos com editores que buscam autores pela rede, caso de Líria:

"A publicação do meu primeiro livro, Borboleta Desfolhada, só foi possível porque o editor conheceu meu blogue e pediu autorização para escolher e publicar meus poemas em Portugal. E foi pelo Facebook que conheci a Silvana de Menezes, excelente ilustradora da editora Lê (ela é escritora também, Prêmio Jabuti 2008 de melhor livro infantojuvenil) que manifestou a vontade de ilustrar meus livros Garimpo (juvenil) e Asa de Passarinho (infantil), que estarão publicados ainda neste primeiro semestre. O livro Olho nu (adulto), a ser publicado pela Patuá, possivelmente até o final do ano, viabilizou-se também por 
intermédio da rede. Isso sem falar nas inúmeras participações nos espaços virtuais."

Já os casos lembrados por editores têm forte apelo em direção às vendas de obras que teriam dificuldades de serem conhecidas do grande público. As redes sociais teriam auxiliado na atração do público, caso de Carlos Henrique Schroeder e Carlos Fialho:

"Criamos (com a E-galáxia) uma coleção de contos chamada Formas breves, que publica um conto por semana, a R\$ 1,99, e qualquer pessoa com acesso à internet pode comprar, nas principais lojas digitais do planeta, como Amazon, Apple Store, Google Play, Saraiva, Cultura e Iba. E nossa única divulgação é pelas redes sociais, principalmente pelo Facebook e Twitter, e a coleção estourou (várias contos entre os mais vendidos de diversas lojas virtuais) graças ao barulho que nós e, também os autores, fazemos nas redes sociais." (Schroeder)

"Em 2006, pedi para 40 diretores de arte, ilustradores e artistas amigos fazerem criações sobre o meu livro E Tudo Mentira Durante 40 dias, enviei e-mails para uma lista de destinatários com a arte do dia. A coisa viralizou de tal forma que vendemos quase 200 exemplares no lançamento. Em 2009, já com redes sociais bombando, fizemos o mesmo com frases de humor. $\mathrm{O}$ livro Mano Celo vendeu 385 na noite de lançamento, recorde da editora até hoje." (Fialho)
Mas é Mário Alex Rosa, escritor, editor e artista plástico, que narra o caso que mais aproxima redes sociais on e off-line, tratando do caso da poetisa mineira Ana Martins Marques, atualmente autora da editora Companhia das Letras:

O caso mais recente, sem dúvida, é o livro $A$ vida submarina da poeta Ana Martins, que ajudei a publicar, editar e divulgar. Não conhecia a Ana, nunca tinha ouvido falar dela, li os originais e gostei muito. Na Scriptum, procuramos convidar críticos de outros estados para escrever os textos de apresentação e isso tem ajudado também na divulgação dos nossos livros. Lembro que o crítico e professor da USP Murilo Marcondes fez a orelha do livro da Ana, o que certamente contribuiu bastante. Alinhamos duas qualidades: a poeta e o crítico. (Mário Alex Rosa)

\section{CONSIDERAÇÕES FINAIS}

O mapa - sempre instável - dos movimentos das redes de edição atuais deve muito aos espaços criados por chats, blogs, redes e microrredes, além de e-mails, que são para comunicação privada (descontando-se as listas!). A instabilidade, aqui, no entanto, não tem conotação ruim. Trata-se mesmo do mecanismo da produção e da edição da literatura, que se move - desde sempre - de acordo com movimentos sociais, históricos e tencnológicos. 
Editores e autores, especialmente os aqui entrevistados, têm consciência dos fluxos em que estão inseridos e de que são, também, protagonistas; sabem que podem empregar novos espaços digitais para potenciar suas produções, do ponto de vista da criação e da difusão; atribuem-se papéis mesclados, o que está bastante distante da visão segundo a qual haveria uma divisão do trabalho que separaria autores e editores. Estes personagens ou "atores sociais do livro" já não se sentam de lados opostos da mesa, quando em negociação. Trabalham juntos, em grande parte, remotamente. E assim vão-se tecendo os fios das redes de edição do século XXI.

\section{REFERÊNCIAS}

ARAÚJO, Diná M. P. Arduíno Bolivar Colección: reflexiones sobre una biblioteca particular. In: CONGRESO INTERNACIONAL LAS EDADES DEL LIBRO, 2012, Cidade do México. Memorias del Congreso Internacional "Las Edades del Libro". México: Coordinación de Humanidades; IIB-BN/Hn; Fondo de Cultura Económica, 2012. v. 1. p. 620-6.

ARAÚJO, Pablo Guimarães de. Uma tecnologia na mão e uma ideia na cabeça: pequenas editoras, autores independentes e as novas possibilidades de publicação de livros. Dissertação (Mestrado em Estudos de Linguagens), Centro Federal de Educação Tecnológica de Minas Gerais, 2013.

BAHLOUL, Joëlle. Lecturas precarias. Estudio sociológico sobre los "poco lectores". Trad. ao espanhol Roberto Cue. Cidade do México: Fondo de Cultura Económica, 2002.
BAYARD, Pierre. Como falar dos livros que não lemos? Trad. Rejane Janowitzer. Rio de Janeiro: Objetiva, 2007.

CASTELLS, Manuel. A sociedade em rede. Roneide Venancio Majer. São Paulo: Paz e Terra, 2007.

CASTELLS, Manuel. A galáxia Internet. Reflexões sobre Internet negócios e sociedade. Trad. ao português europeu de Rita spanha. Lisboa: Fundação Calouste Gulbenkian، 2007a.

MARTINS, Jorge. Profissões do livro. Editores e gráficos, críticos e livreiros. Lisboa: Verbo, 2005

RECUERO, Raquel. A conversação em rede. Comunicação mediada pelo computador e redes sociais na Internet. Porto Alegre: Sulina, 2012.

RECUERO, Raquel. Redes sociais na Internet. Porto Alegre: Sulina, 2009

RIBEIRO, Ana Elisa. "No Brasil, só se entende escrever em jornal" - Clarice Lispector, Fernando Sabino e redes de edição no século XX. In: 90 ENCONTRO NACIONAL DE HISTÓRIA DA MÍDIA, 2013, Ouro Preto. Anais do 9o Encontro Nacional de História da Mídia. Ouro Preto: UFOP Alcar, 2013.

RIBEIRO, Ana Elisa. "Não tem que ser bom editor, tem que ser rápido": redes de edição de Clarice Lispector em meados do séc. XX. In: XXXVI CONGRESSO BRASILEIRO DE CIÊNCIAS DA COMUNICAÇÃO, 2013, Manaus. Anais do XXXVI Congresso Brasileiro de Ciências da Comunicação. Manaus: Intercom, 2013 